\title{
Trace Elements and Chronic Kidney Disease: A Cross-Sectional Study from Jamaica
}

Authors:

Disclosure:

Acknowledgements:

Received:

Accepted:

Keywords:

Citation:
${ }^{*}$ Adwalia Fevrier-Paul, ${ }^{1}$ Adedamola Soyibo, ${ }^{2}$ Nimal De Silva, ${ }^{3}$ Sylvia Mitchell, ${ }^{4}$ Donovan McGrowder, ${ }^{5}$ Mitko Voutchkov'

1. Department of Physics, Faculty of Science and Technology, The University of the West Indies, Kingston, Jamaica

2. Department of Medicine, University Hospital of the West Indies, Kingston, Jamaica

3. Department of Earth and Environmental Sciences, University of Ottawa, Canada

4. The Biotechnology Centre, Faculty of Science and Technology, The University of the West Indies, Kingston, Jamaica

5. Department of Pathology, The University of the West Indies, Kingston, Jamaica *Correspondence to afpaul23@gmail.com

The authors have declared no conflicts of interest. Research grants were received from Office of the Registrar, Graduate Studies \& Research, University of the West Indies, Kingston, Jamaica. Additionally, the Canadian-CARICOM scholarship was awarded by Global Affairs Canada to facilitate collaborative research with the University of Ottawa, Canada.

The authors would like to thank the administration and staff of the Department of Physics for the support they gave to the research project. They would also like to give a special thank you to André Desrochers, Smitarani Mohanty, and Keiko Hattori for facilitating the collaborative research with the University of Ottawa, Canada. Finally, they would like to extend their gratitude to the International Centre for Environmental and Nuclear Sciences, Kingston, Jamaica, and the Tropical Metabolism Research Unit, Caribbean Institute for Health Research, The University of the West Indies, Kingston, Jamaica, for their technical support and the expertise that they gave to this study.

18.02.21

04.05 .21

Biomarker, chronic kidney disease (CKD), strontium, trace element profile.

EMJ Nephrol. 2021:9[1]:79-90.

\section{Abstract}

Background: Several environmental studies have reported that low-level exposure to nephrotoxic elements increases the risk of chronic kidney disease (CKD). In developing countries, finite resources can limit epidemiological studies and environmental risk assessment; however, the unique soil profile in Jamaica has raised some concerns for the potential exposure to populations who are of high risk.

Method: This study investigated the potential for using trace element profiling in CKD, by analysing blood concentration levels of vanadium, chromium, iron, cobalt, copper, zinc, selenium, strontium (Sr), arsenic, barium, cadmium, mercury, and lead. Trace element analysis was conducted using inductively coupled plasma mass spectrometry.

Results: One hundred and fifty-eight individuals were included and were predominantly of African descent (98\%) and their ages ranged from 21 to 90 years old. Three main correlation clusters were evident: firstly, vanadium, chromium, copper, silicon, and selenium, with mercury and barium more distantly related; secondly, lead, arsenic, nickel, and Sr; and thirdly, iron and zinc. Cadmium was an 
outlier. Blood Sr was strongly associated with estimated glomerular filtration rate $(r=-0.83 ; p<0.001)$ and strong linear progression models $\left(r^{2}=0.96 ; p<0.001\right)$. Algorithmic models placed $\mathrm{Sr}$ as the highestranking trace element biomarker (area under the curve: 95.6\%; $p<0.001$ ).

Discussion: The decline in kidney function may result in the retention of non-essential trace elements. Strong corresponding trends between kidney function and blood Sr concentration indicate biomarker potential for a trace element with a unique profile in patients with CKD. Other significant relationships may also be unveiled as CKD biomarkers as trace element profiling is explored in the region.

\section{INTRODUCTION}

The global epidemic of diabetes and hypertension continues to foster the rapid increase of chronic kidney disease (CKD), which has an estimated prevalence of $13.4 \%$ worldwide. ' The Caribbean region situated between the Americas is as vulnerable to these disease trends as anywhere else. In Jamaica, which is the largest Englishspeaking Caribbean island, the prevalence of diabetes and hypertension is 30\% and 35\%, respectively. ${ }^{2}$ At least 150,000 Jamaicans have been estimated to be living with some form of kidney disease, of which approximately 2,700 are cases of CKD. 3,4

The island is unique in that it contains significantly high levels of cadmium (Cd) soil reservoirs, with the highest levels registered at $409 \mathrm{mg} / \mathrm{kg}$. These levels are more than the world's mean soil measurements, which range from 0.005 to 2.900 $\mathrm{mg} / \mathrm{kg} .^{5}$ Environmental studies carried out by the International Centre of Environmental and Nuclear Science, Kingston, Jamaica, detailing the bioaccumulation in staple foods of the Jamaican diet such as sweet potatoes, ginger, and rice, demonstrate the potential exposure pathways for toxic element exposure. ${ }^{6-8}$ Biopsy studies have revealed the deposition of toxic metals in the kidney and liver of cattle reared in those areas. ${ }^{9}$ The purported link of $\mathrm{Cd}$ to kidney disease, as well as the resurgence of industrial mining in recent times, has spurred interest in trace element analysis and related chronic diseases on the island.

Since the discovery of aluminium-induced neurological and bone disease in patients receiving dialysis, trace elements have been studied in relation to kidney disease and therapy. ${ }^{10,11}$ Other studies suggest an increased risk of CKD, hypertension, and diabetes by virtue of low-level chronic exposure to toxic metals. ${ }^{12,13}$

However, few environmental studies have evaluated element trends and their relationship to CKD in black ethnic groups even in international studies, despite the disproportionate burden of CKD that has been highlighted in these populations. ${ }^{14}$ In low-income countries, such an undertaking is of low priority due to lack of financial resources and/or relevant infrastructure.

Trace elements are ubiquitous entities and a fair number of non-essential xenobiotics gain entry into the body via a multitude of ways, including through groundwater (arsenic, strontium, silicon), inhalation of silica dust (silicon), gasoline (lead), cigarette smoke, and soil (cadmium) and food contamination (arsenic, mercury). ${ }^{15}$ Ordinarily, inadvertent intake of non-essential trace elements is neutralised by excretory pathways, and nascent biomolecular mechanisms reduce the likelihood of protracted renal exposure. However, the reduction of renal clearance will likely lead to the progressive accumulation of these nonessential elements in patients with CKD. ${ }^{16}$ Dietary restriction introduced for the management of CKD may further potentiate exposure to nonessential trace elements that are found in high concentrations in the recommended food groups. ${ }^{17}$ The propensity for xenobiotic elements to interfere with cellular processes, inducing cytotoxic responses and causing localised tissue injury while supplanting essential elements and reducing reparatory function, can further exacerbate the metabolic milieu commonly associated with complications of CKD. 18,19 The aim of this study was to investigate the trace element profile for Jamaican patients with CKD.

\section{MATERIALS AND METHODS}

\section{Ethical Statement}

Approval was granted in 2016 from the Medical Ethics Committee of The University of the West 
Indies, from the Ministry of Health, and from the relevant municipal health agencies. Procedures followed were in compliance with the Declaration of Helsinki 1975, as revised in 2013.

\section{Population}

A cross-sectional study was carried out between 2016 and 2019 in Jamaica. Patients with CKD from three major renal clinics in Kingston, St. Ann Parish, and Manchester Parish were recruited; the Kingston clinic receives intake of patients from the southeast region of the island, while the other two clinics receive intake from the northeast and southern regions, respectively. All attendees at the respective clinics were approached and given equal opportunity to participate in the study; however, patients who did not meet inclusion criteria requirements were immediately eliminated from the sample population. Sixtyeight patients with Stage 5 CKD on haemodialysis (CKD-HD) and 61 patients with CKD from Stage 1 to 4 gave prior informed consent to participate in the study and were interviewed. Subsequently, 29 volunteers who did not have CKD were recruited by convenience sampling and gave prior informed consent and were interviewed. Of the eligible candidates, 96 study participants submitted fasting venous blood samples for trace element analysis.

\section{Selection Criteria and Outcomes}

The estimated glomerular filtration rate (eGFR) was calculated using the CKD Epidemiology Collaboration formula. CKD, according to Kidney Disease Increasing Global Outcomes (KDIGO) guidelines, is defined as kidney damage (structural or functional) for $>3$ months with a loss of glomerular function or an eGFR $<60 \mathrm{~mL} /$ $\mathrm{min} / 1.73 \mathrm{~m}^{2}$ and/or the presence of albuminuria (>30 mg). ${ }^{20}$ Patients were classified Stage 1-4 according to KDIGO guidelines. End-stage renal disease (ESRD)/CKD-HD Stage 5 represented in this study was classified as having an eGFR $<15$ $\mathrm{mL} / \mathrm{min} / 1.73 \mathrm{~m}^{2}$ and receiving renal replacement therapy (haemodialysis; HD), ${ }^{20,21}$

A priori evaluation of the subjects without CKD was guided by the following criteria: 21 years of age and older; living in Jamaica for at least 6 months with no known history of irregular elemental exposure through occupation or association; and in good health (on declaration and confirmed by follow-up medical evaluation).
Volunteers who reported heavy drinking, smoking, or heavy mineral supplementation were excluded from this cohort. Of the 29 self-declared non-CKD group, 24 participants were eligible and fell within the reference ranges for systolic and diastolic pressure and renal function indices.

\section{Sample Collection and Handling}

Special care was taken to avoid entry of external contaminants into the blood samples. Blood was extracted into trace-element-free tubes ( $\mathrm{K}_{2}$ EDTA $\mathrm{BD}$ vacutainer, $4.0 \mathrm{~mL}$ ). For patients with CKDHD Stage 5, blood extraction was conducted pre- and post-HD. To reduce additive effects, antiseptic agents containing betadine and iodine derivatives were avoided during sample extraction. Powder-free sterile gloves and $70 \%$ isopropyl alcohol were used during sample extraction and handling. Specimens were stored at $-80{ }^{\circ} \mathrm{C}$ until analysis. Serum samples were also withdrawn and submitted for routine biochemical analyses, including serum creatinine.

\section{Sample Preparation and Elemental Analysis}

All vials and tubes during sample processing were acid washed overnight with $1 \%$ nitric acid $\left(\mathrm{HNO}_{3}\right)$ and rinsed with deionised water. For acid digestion, trace metal grade concentrated $\mathrm{HNO}_{3}$ was submitted to sub-boiling distillation to produce high-purity $\mathrm{HNO}_{3}$. Element-free propylene tubes were used. $2.0 \mathrm{~mL}$ of $\mathrm{HNO}_{3}$ was added to $0.1 \mathrm{~mL}$ of blood in a Teflon vial and digested overnight on a hotplate at $100{ }^{\circ} \mathrm{C}$, evaporated to incipient dryness, and redissolved in $2 \% \mathrm{HNO}_{3}$. Samples were analysed by inductively coupled plasma mass spectrometry on an Agilent 8800 ICP-QQQ (Agilent, Santa Clara, California, USA) for iron ( $F e)$, zinc $(\mathrm{Zn})$, silicon $(\mathrm{Si})$, vanadium $(\mathrm{V})$, chromium ( $\mathrm{Cr}$ ), cobalt (Co), nickel (Ni), copper (Cu), arsenic (As), selenium (Se), strontium ( $\mathrm{Sr}$ ), $\mathrm{Cd}$, barium ( $\mathrm{Ba}$ ), mercury $(\mathrm{Hg})$, and lead $(\mathrm{Pb})$. For ease of discussion, trace elements were grouped as essential and non-essential.

\section{Clinical Evaluation}

Demographic data and medical history were elicited by assisted interview. Physical examination was carried out by trained personnel to acquire anthropometric measurements and blood pressure (BP). Biochemical analysis was 
also performed to establish renal function, and the eGFR was calculated using the CKD Epidemiology Collaboration formula.

\section{Statistical Analysis}

Statistical analysis was performed using Statistical Packages for Social Sciences (SPSS ${ }^{\circledR}$; $\mathrm{IBM}^{\circledR}$, Armonk, New York, United States) software. Baseline clinical characteristics were calculated using the Student's t test for continuous variables. The difference between the non-CKD, CKD Stage 1-4, and ESRD groups was analysed using Kruskal-Wallis test. Statistically significant trace element features were identified by evaluating element concentration and trends based ondiagnosis and severity of CKD. The intradialytic efficacy of the HD process was obtained by finding the difference between the pre- and post-HD blood concentration of participants with Stage 5 CKD undergoing chronic dialysis (CKD-5D):

$\%$ Difference $=-\frac{\text { PreHDconc. }- \text { PostHDconc. }}{\text { PreHDconc. }} * 100$

Spearman's correlation was used to evaluate correlations between trace element levels and age, serum creatinine, and eGFR. For the patients with Stage 5 CDK-HD, trace element correlations with length of HD sessions were also obtained. Partial correlations were adjusted for age and systolic BP to determine associations between trace elements, serum creatinine, and eGFR.

Using MetaboAnalyst 4.0, trace element data were log-transformed and auto-scaled by meancentring and adding the standard deviation of each variable. Three algorithms, including support vector machines, partial least-squares discriminant analysis, and random forest, were used to generate models to identify the most significant trace element features. Multivariate logistic regression models were then constructed using the derived trace element features in models adjusted for age, sex, and hypertension. A p value of $<0.05$ was considered statistically significant.

\section{RESULTS}

\section{Study Population}

Study participants were predominantly of African descent (98\%). The average age of the study participants was 51 years (range: 20-90). The average systolic BP of the study population was $146 \mathrm{mmHg}$ (range: 96-235). The mean age, systolic BP, and blood glucose were highest among patients with Stage 5 CKD as compared to other study participants. In the study overall, there was an equal male-female distribution (50\% each); however, there was a larger female representation within CKD Stages 1-4, while males accounted for twice the number of females in the CKD-5D group. Hypertension was the most common comorbidity for patients with CKD (87\%), followed by diabetes (38\%). Of the patients with CKD-5D, 85\% attended bi-weekly dialysis sessions, $13 \%$ attended dialysis sessions three days per week, and $2 \%$ attended only one dialysis session per week.

\section{Trace Element Analysis}

Blood Sr levels progressively increased with declining kidney function $(p<0.001)$. Table $1 \mathrm{~A}$ shows other elements such as Cd (highest), Ba, and $\mathrm{Si}$ (lowest) in the patient group with CKD Stages 1-4 $(p<0.001)$ as compared to the other groups; the table also shows Fe and Zn (highest), and Co (lowest) in the patient group without CKD as compared to the other groups $(p<0.001)$. Linear progression models for geometric mean blood concentration for the first four stages of CKD produced a strong linear progression for $\mathrm{Sr}\left(r^{2}=0.96\right)$, and moderate/mild linearity for $\mathrm{Si}$ $\left(r^{2}=0.65\right), \mathrm{Fe}\left(r^{2}=0.63\right), \mathrm{Cd}\left(r^{2}=0.63\right), \mathrm{Co}\left(r^{2}=0.58\right)$, Ba $\left(r^{2}=0.53\right)$, and $\mathrm{Cr}\left(r^{2}=0.51\right)$. However, most elements fit a polynomial trend better: $\mathrm{Cu}\left(r^{2}=31\right)$, As $\left(r^{2}=0.16\right), \mathrm{Hg}\left(r^{2}=0.15\right)$, Se $\left(r^{2}=0.13\right), \mathrm{Zn}\left(r^{2}=0.10\right)$, $\mathrm{V}\left(r^{2}=0.10\right), \mathrm{Pb}\left(r^{2}=0.04\right)$, and $\mathrm{Ni}\left(r^{2}=0.00\right)$.

The following non-essential elements showed significant intradialytic changes: decreased As (46\%; $p<0.001)$ and increased $\mathrm{Sr}$ (56\%; $\mathrm{p}<0.001)$. There was no significant difference in the mean essential trace element levels pre- and post-HD; however, $\mathrm{Sr}(r=0.362)$, Se $(r=0.374), \mathrm{Pb} \quad(r=0.321)$, and Co $(r=0.369)$ showed significant positive associations with length of HD in post-HD samples. Similarly, patients on thrice-weekly dialysis sessions were more likely to have increased $\mathrm{Sr}$ levels $(r=0.273)$ compared to other patients on HD. 
Table 1A: Trace element concentrations in whole blood for study participants.

\begin{tabular}{|c|c|c|c|c|c|c|c|}
\hline \multirow[t]{2}{*}{ Element } & \multirow[t]{2}{*}{ Group* } & \multirow{2}{*}{$\begin{array}{l}\text { Geomean } \\
(\mu \mathrm{g} / \mathrm{L})\end{array}$} & \multirow{2}{*}{$\begin{array}{l}S D \\
(\mu \mathrm{g} / \mathrm{L})\end{array}$} & \multirow{2}{*}{$\begin{array}{l}\text { Median } \\
(\mu \mathrm{g} / \mathrm{L})\end{array}$} & \multicolumn{2}{|c|}{ Range ( $\mu \mathrm{g} / \mathrm{L})$} & \multirow[t]{2}{*}{ Group ${ }^{+}$} \\
\hline & & & & & Min & Max & \\
\hline \multirow[t]{3}{*}{$\mathrm{Sr}$} & 1 & 16.65 & 12.04 & 15.35 & 13.45 & 26.62 & $2>1 \ddagger$ \\
\hline & 2 & 38.03 & 18.26 & 40.04 & 17.24 & 82.83 & $3>1 \ddagger$ \\
\hline & 3 & 338.80 & 224.80 & 441.70 & 34.97 & 909.00 & $3>2 \S$ \\
\hline \multirow[t]{3}{*}{$\mathrm{Cd}$} & 1 & 0.46 & 0.85 & 0.44 & 0.05 & 3.54 & $2>1 \ddagger$ \\
\hline & 2 & 247.25 & 70.50 & 230.80 & 170.00 & 484.20 & $2>3 \ddagger$ \\
\hline & 3 & 1.13 & 1.31 & 1.31 & 0.06 & 6.83 & $3>1^{* *}$ \\
\hline \multirow[t]{3}{*}{$\mathrm{Ba}$} & 1 & 51.06 & 37.50 & 52.55 & 7.03 & 332.60 & $3>1^{* *}$ \\
\hline & 2 & 4.02 & 34.69 & 4.48 & 0.00 & 189.30 & $1>2 \ddagger$ \\
\hline & 3 & 72.63 & 77.10 & 81.00 & 9.20 & 161.40 & $3>2 \ddagger$ \\
\hline \multirow[t]{3}{*}{$\mathrm{Hg}$} & 1 & 1.35 & 1.52 & 1.18 & 0.37 & 9.85 & $3>1^{* *}$ \\
\hline & 2 & 0.43 & 0.39 & 0.46 & 0.02 & 1.71 & $1>2 \ddagger$ \\
\hline & 3 & 1.94 & 1.52 & 1.96 & 0.34 & 6.45 & $3>2 \ddagger$ \\
\hline \multirow[t]{3}{*}{$\mathrm{Pb}$} & 1 & 3.87 & 23.44 & 5.71 & 0.15 & 105.70 & $2>1^{* *}$ \\
\hline & 2 & 18.12 & 9.90 & 18.31 & 6.06 & 40.61 & $3>1 \ddagger$ \\
\hline & 3 & 21.97 & 23.44 & 29.52 & 0.01 & 19.51 & $3>2 \ddagger$ \\
\hline \multirow[t]{3}{*}{ As } & 1 & 1.01 & 1.20 & 1.12 & 0.10 & 4.30 & $2>1^{* *}$ \\
\hline & 2 & 4.78 & 4.68 & 4.41 & 1.12 & 22.36 & $3>1 \ddagger$ \\
\hline & 3 & 5.91 & 3.93 & 6.08 & 1.51 & 18.89 & $3>2 \ddagger$ \\
\hline \multirow[t]{3}{*}{$\mathrm{Ni}$} & 1 & 2.23 & 66.84 & 1.50 & 0.11 & 279.00 & $2>1^{* *}$ \\
\hline & 2 & 14.46 & 44.79 & 16.97 & 0.43 & 231.20 & $3>1 \ddagger$ \\
\hline & 3 & 12.15 & 29.59 & 11.10 & 3.06 & 149.90 & $2>3 \ddagger$ \\
\hline \multirow[t]{3}{*}{$\mathrm{Si}$} & 1 & $4,377.30$ & $3,688.00$ & $9,089.00$ & 29.00 & 12148.00 & $3>1^{* *}$ \\
\hline & 2 & $1,059.00$ & 715.70 & 982.40 & 152.00 & 3793.00 & $1>2 \ddagger$ \\
\hline & 3 & $8,124.40$ & $2,760.00$ & $7,917.00$ & 4161.00 & 15218.00 & $3>2 \ddagger$ \\
\hline \multirow[t]{3}{*}{$\mathrm{Fe}$} & 1 & 414.58 & 82.28 & 428.60 & 221.10 & 592.80 & $2>3^{* *}$ \\
\hline & 2 & 394.81 & 70.13 & 408.90 & 200.20 & 511.70 & $1>3 \ddagger$ \\
\hline & 3 & 208.88 & 103.40 & 219.90 & 75.23 & 439.50 & $1>2 \ddagger$ \\
\hline \multirow[t]{3}{*}{$\mathrm{Zn}$} & 1 & 6.14 & 1.49 & 6.13 & 3.45 & 9.20 & $3>2^{* *}$ \\
\hline & 2 & 6.10 & 1.97 & 6.03 & 3.28 & 13.11 & $1>3 \ddagger$ \\
\hline & 3 & 4.12 & 1.76 & 4.12 & 1.93 & 8.65 & $1>2 \ddagger$ \\
\hline \multirow[t]{3}{*}{$\mathrm{Cu}$} & 1 & 1221.20 & 447.60 & $1,180.00$ & 800.10 & $2,783.00$ & $1>3^{* *}$ \\
\hline & 2 & 983.07 & 234.00 & 972.80 & 674.10 & $1,625.00$ & $1>2^{* *}$ \\
\hline & 3 & $1,159.70$ & 429.60 & $1,138.00$ & 498.90 & $2,446.00$ & $3>2^{* *}$ \\
\hline \multirow[t]{3}{*}{$\mathrm{Se}$} & 1 & 212.38 & 56.22 & 228.10 & 72.49 & 304.10 & $1>3^{* *}$ \\
\hline & 2 & 186.11 & 61.96 & 165.40 & 103.70 & 370.00 & $3>2 \S$ \\
\hline & 3 & 193.08 & 70.92 & 171.30 & 36.39 & 361.20 & $1>2^{* *}$ \\
\hline
\end{tabular}


Table 1A (Continued): Trace element concentrations in whole blood for study participants.

\begin{tabular}{|c|c|c|c|c|c|c|c|}
\hline \multirow[t]{2}{*}{ Element } & \multirow[t]{2}{*}{ Group* } & \multirow{2}{*}{$\begin{array}{l}\text { Geomean } \\
(\mu \mathrm{g} / \mathrm{L})\end{array}$} & \multirow{2}{*}{$\begin{array}{l}\text { SD } \\
(\mu g / L)\end{array}$} & \multirow{2}{*}{$\begin{array}{l}\text { Median } \\
(\mu \mathrm{g} / \mathrm{L})\end{array}$} & \multicolumn{2}{|c|}{ Range $(\mu \mathrm{g} / \mathrm{L})$} & \multirow[t]{2}{*}{ Group ${ }^{+}$} \\
\hline & & & & & Min & Max & \\
\hline \multirow[t]{3}{*}{$\mathrm{Cr}$} & 1 & 21.46 & 18.54 & 44.38 & 0.65 & 56.97 & $3>1^{* *}$ \\
\hline & 2 & 12.02 & 30.62 & 12.23 & 1.02 & 153.50 & $1>2 \S$ \\
\hline & 3 & 23.49 & 37.03 & 35.31 & 3.04 & 146.70 & $3>2^{* *}$ \\
\hline \multirow[t]{3}{*}{ Co } & 1 & 0.67 & 1.11 & 0.52 & 0.05 & 5.69 & $2>1 \ddagger$ \\
\hline & 2 & 1.71 & 2.12 & 0.87 & 0.01 & 7.74 & $3>1 \S$ \\
\hline & 3 & 1.64 & 1.01 & 1.75 & 0.23 & 3.69 & $2>3^{* *}$ \\
\hline \multirow[t]{3}{*}{ V } & 1 & 4.00 & 3.67 & 7.28 & 0.04 & 13.59 & $3>1^{* *}$ \\
\hline & 2 & 2.46 & 11.36 & 2.60 & 0.31 & 58.41 & $3>2 \S$ \\
\hline & 3 & 6.36 & 3.27 & 7.76 & 1.40 & 13.59 & $1>2^{* *}$ \\
\hline
\end{tabular}

*Group 1: no CKD; Group 2: CKD Stage 1-4; Group 3: CKD Stage 5.

+Group comparison; group comparisons have an adjusted $p$ value.

ładjusted $p$ value $<0.001$

Sadjusted $p$ value $<0.05$

**adjusted $p$ value: no significance.

As: arsenic; Ba: barium; Cd: cadmium; CKD: chronic kidney disease; Co: cobalt; Cr: chromium; Cu: copper; Fe: iron; Hg: mercury; Ni: nickel; Pb: lead; Se: selenium; Si: silicon; Sr: strontium; V: vanadium; Zn: zinc.

Figure 1 shows the correlations between various trace elements and age. Three main correlation clusters were evident: firstly, V, Cr, Cu, Si, and Se, with $\mathrm{Hg}$ and $\mathrm{Ba}$ more distantly related; secondly, $\mathrm{Pb}, \mathrm{As}, \mathrm{Ni}$, and $\mathrm{Sr}$; and thirdly, Fe and $\mathrm{Zn}$. Cd was an outlier. The first two clusters were more closely related than the third. Blood $\mathrm{Sr}$ was positively correlated with several non-essential elements including $\mathrm{As}(r=0.560 ; \mathrm{p}<0.001)$ and $\mathrm{Pb}(r=0.550$; $p<0.001)$, but negatively correlated with essential elements such as Fe $(r=-0.590 ; p<0.001)$ and $\mathrm{Zn}(r=-0.350 ; p<0.001)$. As a general finding, essential trace elements correlated positively with each other and negatively with nonessential elements. The exception to this trend was observed with Co, however, which correlated significantly with several non-essential elements including $\mathrm{Pb}, \mathrm{As}$, and $\mathrm{Sr}$. The strongest correlations were observed between $\mathrm{Fe}$ and $\mathrm{Zn}$ $(r=0.770 ; p<0.001)$, and $\mathrm{Cd}$ and $\mathrm{Si}(r=-0.720$; $\mathrm{p}<0.001)$. The highest negative correlation was found between eGFR and $\mathrm{Sr}$ ( $r=-0.830$; $\mathrm{p}<0.001)$. This significant correlation persisted after adjusting for age and systolic BP ( $r=-0.580$; $\mathrm{p}<0.001$ ). Non-essential metals such as $\mathrm{Pb}, \mathrm{Ni}$, $\mathrm{As}$, and $\mathrm{Hg}$ all showed inverse association with eGFR, unlike Fe and Zn, which showed positive association. However, As $(r=-0.403 ; p<0.001)$, $\mathrm{Pb} \quad(r=-0.280 ; p<0.05)$, Fe $(0.569 ; p<0.001)$, and $\mathrm{Zn}(0.301 ; \mathrm{p}<0.05)$ remained significant after adjusting for age and systolic BP. Serum creatinine showed inverse relationships to $\mathrm{Fe}$ $(r=-0.650 ; p<0.001)$ and $\mathrm{Zn}(r=-0.390 ; p<0.05)$, but a positive association with $\mathrm{Sr}(r=0.720$; $\mathrm{p}<0.001$ ) after adjusting for age and systolic BP.

All three algorithmic models ranked $\mathrm{Sr}$ in the top tier of the trace element profile. Further logistic regression analyses performed using partitioning of eGFR $<60 \mathrm{~mL} / \mathrm{min} / 1.73 \mathrm{~m}^{2}$ (Table 1B) and eGFR $<45 \mathrm{~mL} / \mathrm{min} / 1.73 \mathrm{~m}^{2}$ affirmed a significant association between CKD diagnosis and increased blood Sr levels. A receiver operator curve derived for $\mathrm{Sr}$ (Figure 2) showed the best cut-off for a CKD diagnosis at a Sr concentration of $22.90 \mu \mathrm{g} / \mathrm{L}(\mathrm{p}<0.0001$; standard error: 0.023$)$. 


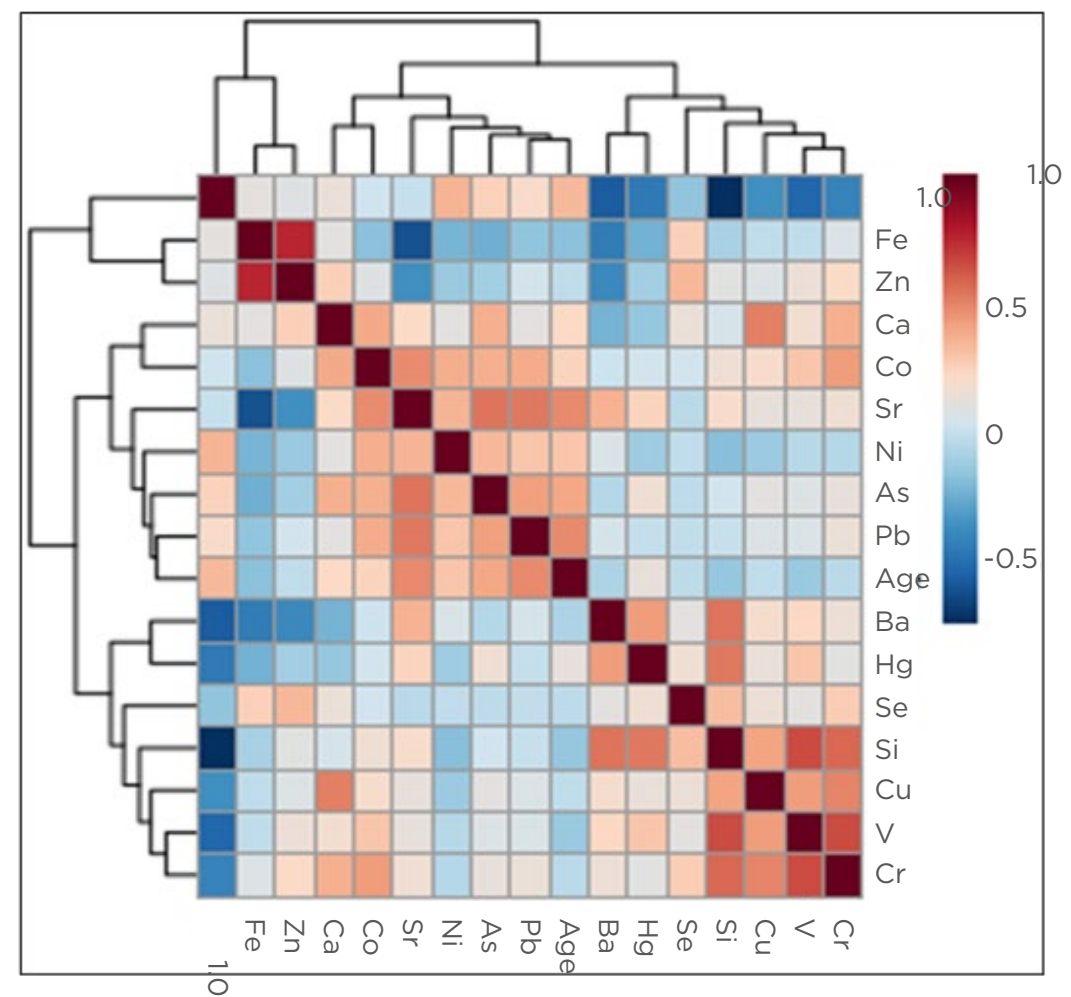

Figure 1: Heat map denoting correlations between age and trace elements.

As: arsenic; Ba: barium; Ca: calcium; Cd: cadmium; Co: cobalt; Cr: chromium; Cu: copper; Fe: iron; Hg: mercury; Ni: nickel; Pb: lead; Se: selenium; Si: silicon; Sr: strontium; V: vanadium; Zn: zinc.

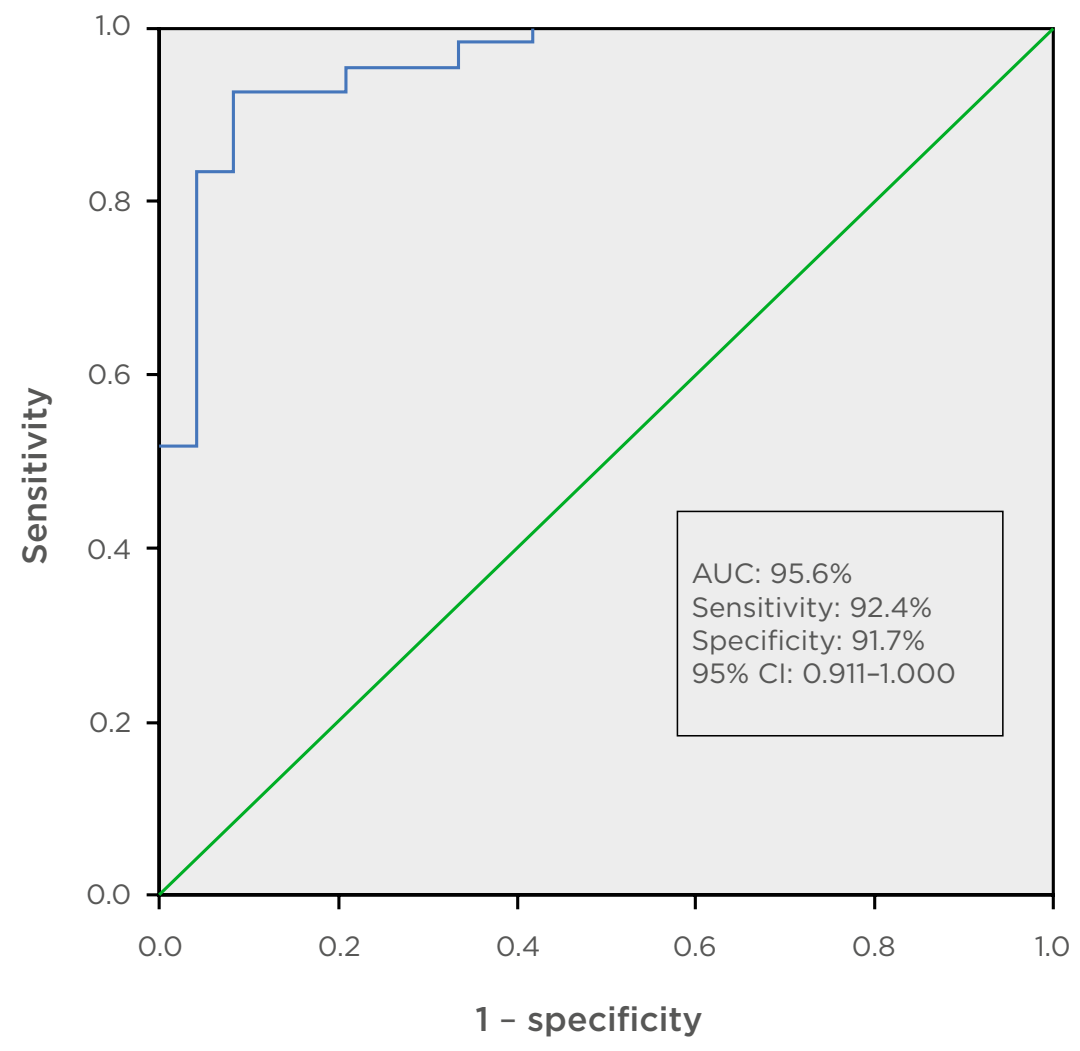

Figure 2: Receiver operator curve for strontium as a potential marker for chronic kidney disease.

AUC: area under the curve; $\mathrm{Cl}$ : confidence interval. 
Table 1B: Significant features of trace elements and odds ratio with chronic kidney disease.

\begin{tabular}{|c|c|c|c|}
\hline Variables & Odds ratio $(95 \% \mathrm{Cl})$ & Significance & Model parameters \\
\hline \multicolumn{4}{|c|}{ Univariate model } \\
\hline Blood Pb & $2.838(0.644-12.505)$ & 0.168 & \multirow[t]{6}{*}{$\mathrm{N} / \mathrm{A}$} \\
\hline Blood Cd & $3.437(0.770-15.341)$ & 0.106 & \\
\hline Blood Sr & $14.618(2.840-75.237)$ & 0.001 & \\
\hline Blood As & $3.100(0.762-12.617)$ & 0.114 & \\
\hline Blood Fe & $0.836(0.149-4.691)$ & 0.838 & \\
\hline Blood Zn & 0.181 (0.032-1.035) & 0.055 & \\
\hline \multicolumn{4}{|c|}{ Multivariate model 1} \\
\hline Blood Sr & $24.229(5.810-101.040)$ & $<0.001$ & \multirow{3}{*}{$\begin{array}{l}\text { Model fitting: significant } \\
\text { Goodness of fitt: no } \\
\text { Significant predictors (LR): Sr, } \\
\text { Cd } \\
\text { Predictive accuracy: } 79.8 \%\end{array}$} \\
\hline Blood Cd & $3.621(1.006-13.034)$ & 0.049 & \\
\hline Blood Pb & $2.221(0.664-7.421)$ & 0.195 & \\
\hline \multicolumn{4}{|c|}{ Multivariate model 2} \\
\hline Blood As & 4.756 (1.397-16.191) & 0.013 & \multirow{3}{*}{$\begin{array}{l}\text { Model fitting: significant } \\
\text { Goodness of fitt: yes } \\
\text { Significant predictors (LR): As, } \\
\text { Sr } \\
\text { Predictive accuracy: } 82.0 \%\end{array}$} \\
\hline Blood Sr & $14.871(4.008-55.176)$ & $<0.001$ & \\
\hline Blood Pb & $1.962(0.564-6.823)$ & 0.289 & \\
\hline \multicolumn{4}{|c|}{ Multivariate model 3} \\
\hline Blood Sr & $11.672(2.749-49.551)$ & 0.001 & \multirow{3}{*}{$\begin{array}{l}\text { Model fitting: significant } \\
\text { Goodness of fitt: no } \\
\text { Significant predictors (LR): As, } \\
\text { Age, Sr } \\
\text { Predictive accuracy: } 92.0 \%\end{array}$} \\
\hline Age & $15.992(3.713-68.886)$ & $<0.001$ & \\
\hline Blood As & $5.969(1.441-24.721)$ & 0.014 & \\
\hline \multicolumn{4}{|c|}{ Multivariate model 4} \\
\hline Blood Sr & $9.895(1.939-50.485)$ & 0.006 & \multirow{2}{*}{$\begin{array}{l}\text { Model fitting: significant } \\
\text { Goodness of fitt: mixed } \\
\text { Significant predictors (LR): As, } \\
\text { Sr } \\
\text { Predictive accuracy: } 90.9 \%\end{array}$} \\
\hline Blood As & $6.294(1.078-36.753)$ & 0.041 & \\
\hline
\end{tabular}

${ }^{*}$ Compares the full model containing all the predictors against a null model.

${ }^{+}$Contains deviance and Pearson chi square tests. A mixed result indicates features do not agree on whether the data fits the model well.

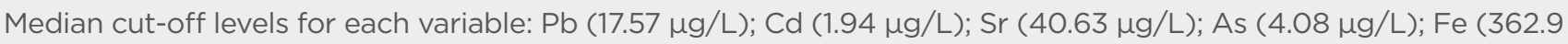
$\mu \mathrm{g} / \mathrm{L}) ; \mathrm{Zn}(5.94 \mu \mathrm{g} / \mathrm{L})$. Multivariate models follow top-ranking features derived in previous analysis. Multivariate model 4: adjusted for age, gender, and systolic blood pressure.

As: arsenic; Cd: cadmium; Cl: confidence interval; Fe: iron; LR: likelihood ratio; N/A: not applicable; Pb: lead; Sr: strontium; Zn: zinc. 


\section{DISCUSSION}

This study found that blood Sr levels increased significantly with a corresponding decline in kidney function. Blood Sr levels rose in patients with CKD-5D even after HD, suggesting a veritably higher exposure risk as compared to subjects without CKD. The strong linear progression with increasing severity of kidney disease and associations with HD treatments strongly suggest that the cumulative trend is associated with increased retention of Sr because of interventional treatment peculiar to patients with ESRD. A similar finding by Schrooten et al. ${ }^{22}$ reported significantly high $\mathrm{Sr}$ levels in a study involving 34 dialysis centres and mainly attributed uptake to be from dialysate fluid or from administration of vitamin $D$ supplements and phosphate binders. If so, patients on HD would be more vulnerable to $\mathrm{Sr}$ exposure due to increased renal retention and chronic intake of dietary supplements and medications that contain Sr. In healthy individuals, $\mathrm{Sr}$ is preferentially excreted over calcium (Ca) despite being absorbed at lower levels by comparison; however, in CKD, as renal excretion of $\mathrm{Sr}$ declines, excretion rates become comparable to that of $\mathrm{Ca}$ and competes with $\mathrm{Ca}$ for bone absorption. ${ }^{23-25}$ Under the deficient conditions of $\mathrm{Ca}$, vitamin $\mathrm{D}$, and/or phosphorus and reduced serum protein, $\mathrm{Sr}$ absorption increases and can precipitate strontium rickets. ${ }^{26,27}$ As a strong precedent has been set for its involvement in osteoporosis and fracture risk assessment, the association between $\mathrm{Sr}$ and mineral bone disease is an equally relevant cause for further research. What is evidently a direct relationship between $\mathrm{Sr}$ and kidney disease is extremely promising as a potential marker.

$\mathrm{Pb}$ and $\mathrm{Cd}$ also compete with $\mathrm{Ca}$ for the binding sites on transport proteins; however, they do not have the equivalent ionic mimicry that $\mathrm{Sr}$ has with $\mathrm{Ca}^{28}$ A series of studies performed by the National Health and Nutrition Examination Survey (NHANES), Centers for Disease Control and Prevention (CDC), showed positive associations between nephrotoxins $\mathrm{Cd}$ and $\mathrm{Pb}$ and $\mathrm{CKD}$, including Navas-Acien et al. ${ }^{29}$ and Ferraro et al. ${ }^{30}$ who demonstrated an inverse relationship between $\mathrm{Cd}$ and $\mathrm{Pb}$ and $\mathrm{CKD}$, and direct associations of $\mathrm{Cd}$ with albuminuria and eGFR. Buser et al. ${ }^{12}$ confirmed these findings, relating inverse relationships of $\mathrm{Pb}$ and $\mathrm{Cd}$ to eGFR. ${ }^{12}$ However, Kim et al. ${ }^{31}$ found that only exposure of $\mathrm{Cd}$ was associated with CKD risk in patients from Korea with diabetes or hypertension, despite registering higher mean blood levels of $\mathrm{Cd}$ and $\mathrm{Pb}$ as compared to their counterparts from the USA. Differences in sources of exposure and genetic make-up, among other factors, may explain these discrepancies. In some models, eGFR was also inversely related to blood As. When investigating As, the Strong Heart Study ${ }^{29}$ revealed significantly lower urinary excretion rates of $A s$ in patients with CKD, suggesting retention of the trace element was a factor in As. Palaneeswari et al. ${ }^{32}$ suggest that their results showing elevated As in 50 patients with ESRD may be the cumulative effect of decreased renal excretion, among other reasons.

These trace elements have known nephrotoxic potential and a strong affinity for renal tissue, employing different mechanisms by which they interact and interfere with resident signalling molecules, transport proteins, and organelle function to cause kidney injury. ${ }^{33,34}$ Like Buser et al., ${ }^{12}$ the present study concludes that reverse causality is primarily responsible for the overall increase of non-essential element levels observed in patients with CKD. Simply put: reduced excretion results in increased retention. Other mechanisms may be at play, selectively increasing $\mathrm{Sr}$ blood levels in comparison to that of other non-essential elements; however, the inverse relationship with eGFR can be utilised to monitor kidney function.

The reports on comparative trends of essential elements were generally more diverse. In this study, only $\mathrm{Fe}$ and $\mathrm{Zn}$ showed initial significant associations with CKD. However, after adjustments for age, sex, and BP, these associations were not statistically significant. Consequently, the purported accumulation of $\mathrm{Cr}$ and $\mathrm{V}$ reported in other studies was not observed in this study. Tonelli et al. ${ }^{16}$ in a meta-analysis of 128 studies (patients per study ranged from 6 to 456 patients; median: 24) determined that $\mathrm{Cu}$, $\mathrm{Cr}$, and $\mathrm{V}$ blood levels were increased in patients on HD, while decreased Se and Zn trends were common. Another review by Jankowska et al. ${ }^{35}$ contended that decreased $\mathrm{Zn}$ and Se and elevated $\mathrm{Cu}$ levels are associated with CKD. However, previous studies by Prodanchuk et al., ${ }^{36}$ which did not include Fe levels, reported 
an increase in $\mathrm{Cu}(\mathrm{p}=0.114), \mathrm{Cr}(\mathrm{p}<0.001), \mathrm{Zn}$ $(p<0.001)$, and $V(p<0.001)$ and a decrease in Se $(p<0.05)$ in 41 patients with ESRD. Dlugaszek et al. ${ }^{37}$ countered with an investigation of $\mathrm{Fe}, \mathrm{Zn}, \mathrm{Cu}$, and $\mathrm{Cr}$ in serum, erythrocytes, and hair from 31 patients. While elevated levels of $\mathrm{Cr} \quad(p<0.001)$ and Fe $(p>0.05)$ were displayed in each measurement, the inverse trend $(p>0.05)$ was apparent in hair (decreased $\mathrm{Zn}$ and increased $\mathrm{Cu}$ ) when compared to serum and erythrocytes. Lokesh et al.,38 conversely, reported decreases in Se $(p=0.217)$ and increases in $\mathrm{Cr}(p<0.001)$ in 40 patients with ESRD; Fe, Zn, V, and $\mathrm{Cu}$ were not included in this analysis. Raoofi et al. ${ }^{39}$ claimed significant decreases in both serum $\mathrm{Cu}$ and $\mathrm{Zn}$ in patients with ESRD, while Balla and Ismail ${ }^{40}$ concluded HD increased serum Zn and decreased serum $\mathrm{Cu}$, though $\mathrm{Zn}$ levels remained deficient in ESRD as compared to controls. ${ }^{39,40}$

The phenomenon of interrelationships between trace elements was observed in this study. Generally, the authors postulated that antagonistic relationships between and among trace elements were partly responsible for their observations apart from the eGFR. Few studies have evaluated the significant clinical outcomes associated with those trace element findings; however, Tonelli et al., ${ }^{17}$ in a prospective longitudinal study, evaluated several clinical outcomes and reported significant associations between risk of mortality and increased hospitalisations with lower concentrations of Se. ${ }^{17}$

Generally, lower levels of trace elements with protective biological properties such as $\mathrm{Fe}, \mathrm{Zn}$, and $\mathrm{Se}$ are observed in patients with chronic diseases, a consequence of increased mobilisation to counter oxidising events precipitated by or causing chronic disease. ${ }^{41}$ As a consequence, diminished levels of essential elements increase the susceptibility for infection, oxidative stress, and proinflammatory processes. ${ }^{35,42,43}$ The nonlinear trends observed indicate a more complex interplay in the pathophysiology of CKD and inadequate recovery mechanisms in more severe disease, as well as antagonistic relationships with non-essential elements.

This study's findings provide a compelling case to pursue validation and/or classification studies for the association of $\mathrm{Sr}$ as a biomarker of CKD.As this was the first trace element profiling study carried out among patients with CKD in Jamaica (and the wider Caribbean region), this study provided unique insight to previously unknown associations, and the collaborative framework established during this study provides an optimistic outlook for follow-up studies. However, the lack of funding presented the greatest challenge and limited the sample size of the study population. This prohibited the involvement of participants from rural parishes bordering the island, particularly to the west. As a result, study findings cannot be applied to the entire CKD population in Jamaica. Furthermore, the cross-sectional design of the study does not allow the case for causation to be made. It also does not adequately explore the potential risk for progression of CKD. While it can provide a baseline for further work, a longitudinal approach to investigate trace element levels in relation to the decline of kidney function would better capture this relationship. In so doing, related adverse health outcomes can be assessed as secondary endpoints. Additionally, parameters that may contribute to the trace element constitution of subjects should be accounted for in future studies. These include lifestyle habits, occupational exposure, and drug exposure, amalgam or prosthetic use.

Data related to recreational/prescription drug and oral supplement intake and other therapeutic options used by patients with CKD should also be accounted for, particularly those highlighted in studies as potential sources of exposure. Exposure assessment should include phosphate binders, vitamin D, and other commonly consumed dietary supplements and a comprehensive trace element profile of dialysate fluid used during HD therapy. The prevalence of CKD and seasonal and dietary factors should also be evaluated for their potential role in observed trace element trends in the general population. It may be that trace element profiles for CKD vary based on geographical locations. As such, national biomonitoring surveys should be performed to establish reference intervals to permit the identification of abnormal trace element findings and subsequent classification as excess or deficient levels accordingly.

\section{CONCLUSION}

The association between blood $\mathrm{Sr}$ and CKD has not been a finding widely discussed in published 
work. Certainly, in the Caribbean it is a novel concept that could expand the use of the trace element profiles in the biomarker analysis of CKD, particularly if these associations are independent of external factors unrelated to the disease pathophysiology. Researchers in the region should be encouraged to explore further trace element relationships, and perform risk analysis of high-risk groups for chronic disease and potential sources of exposure to non-essential and nephrotoxic trace elements.

\section{References}

1. LV J, Zhang L. Prevalence and disease burden of chronic kidney disease. Adv Exp Med Bio. 2019;1165:3-15.

2. Jamaica Health and Lifestyle Survey III (2016 - 2017). Preliminary key findings Jamaica. 2018.

3. Jamaica Observer. Myers G. The uphill battle with kidney disease. 2015. Available at: https://www. jamaicaobserver.com/news/theuphill-battle-with-kidney-failure_183 25697\&template=MobileArticle Last accessed: 5 May 2021

4. Soyibo A. In prevalence of chronic kidney disease in the Caribbean. West Indian Med J. 2011;60(4):46470. Update. Supporting national advocacy in the lead-up to the 2018 high-level meeting on NCDs: towards $25 * 25$ and the sdgss. targeting chronic non-communicable diseases in the caribbean. Knutsford Court Hotel, 2019. Healthy Caribbean NCD Forum. 2018.

5. Lalor G et al. Heavy Metals in Jamaica. Part 3: The distribution of cadmium in Jamaican soils. Rev Int Contam Ambient. 1998;14(1):7-12.

6. Howe A et al. Elemental composition of Jamaican foods 1: a survey of five food crop categories. Environ Geochem Health. 2005;27(1):19-30.

7. Antoine $\mathrm{J}$ et al. Assessment of the potential health risks associated with the aluminium, arsenic, cadmium and lead content in selected fruits and vegetables grown in Jamaica. Tox Rep. 2017;4:181-7.

8. Sanderson D et al. Bioaccumulation of cadmium in potato tuber grown on naturally high levels cadmium soils in Jamaica. Sci Total Environ. 2019;649:909-15.

9. Lalor $\mathrm{G}$ et al. Cadmium levels in kidney and liver of Jamaicans at autopsy. West Indian Med J. 2004;53(2):76-80

10. History of Nephrology; Farrell E, Turner N. Aluminium Poisoning. 2013. Available at: http:// historyofnephrology.blogspot. com/2013/02/aluminium-poisoning. html. Last accessed: 5 May 2021.

11. Altmann P. Aluminium toxicity in dialysis patients: no evidence for a threshold serum aluminium concentration. Nephrol Dial
Transplant. 1993;8(1):25-34.

12. Navas-Acien A et al. Blood cadmium and lead and chronic kidney disease in US adults: a joint Analysis. Am Epidemiol. 2009;170(9):1156-64.

13. Buser $\mathrm{M}$ et al. Urinary and blood cadmium and lead and kidney function: NHANES 2007-2012. Int J Hyg Environ Health. 2016;219(3):2667

14. Muntner P et al. Blood lead and chronic kidney disease in the general United States population: results from NHANES III. Kidney Int. 2003;63(3):1044-50.

15. Soderland P et al. Chronic kidney disease associated with environmental toxins and exposures. Adv Chronic Kidney Dis. 2010;1(3)254-64

16. Tonelli $\mathrm{M}$ et al. Trace elements in hemodialysis patients: a systematic review and meta-analysis. BMC Medicine. 2009;7(1):25.

17. Tonelli $\mathrm{M}$ et al. Concentrations of trace elements and clinical outcomes in hemodialysis patients: a prospective cohort study. Clin J Am Soc Nephrol. 2018;13(6):907-15.

18. Barbier $O$ et al. Effect of heavy metals on, and handling by, the kidney. Nephron Physiol. 2005;99(4):105-10.

19. Prasanth $L$ et al. A review on role of essential trace elements in health and disease. Dr NTR University Health Sciences. 2015;4(2):75-85.

20. KDIGO. Clinical practice guidelines for the evaluation and management of chronic kidney disease. 2013;3(1).

21. UpToDate; Levey A, Inker L. Definition and staging of chronic kidney disease in adults. Available at: https://www. uptodate.com/contents/definitionand-staging-of-chronic-kidneydisease-in-adults. Last accessed: December 2020

22. Schrooten I et al. Increased serum strontium levels in dialysis patients: an epidemiological survey. Kidney Int. 1999;56(5):1886-92.

23. Comar $\mathrm{C}$ et al. Strontium metabolism and strontium-calcium discrimination in man. Exp Bio Med. 1957;95(2):38691.

24. Dow E, Stanbury J. Strontium and calcium metabolism in metabolic bone diseases. J Clin Invest. 1960;39(6):885-903.

25. Spencer $\mathrm{H}$ et al. Strontium and calcium metabolism in man. J Clin Invest. 1957;36(5):680-88.

26. Blaschko S et al. Strontium substitution for calcium in lithogenesis. J Urol. 2013;189(2):7359.

27. Bonjour $\mathrm{J}$ et al. Minerals and vitamins in bone health: the potential value of dietary enhancement. Br J Nutr. 2009;101(11):1581-96

28. Fogelman I, Blake G. Strontium ranelate for the treatment of osteoporosis. BMJ. 2005;330(7505):1400-1.

29. Navas-Acien A et al. Urine arsenic concentrations and species excretion patterns in American Indian communities over a 10-year period: the Strong Heart Study. Env Health Perspect. 2009;117(9):1428-33.

30. Ferraro P et al. Low level exposure to cadmium increases the risk of chronic kidney disease: Analysis of the NHANES 1999-2006. BMC Public Health. 2010;10(1).

31. Kim N et al. Environmental heavy metal exposure and chronic kidney disease in the general population. $J$ Korean Med Sci. 2015;30(3)272.

32. Palaneeswari S et al. Chronic kidney disease - effect of oxidative stress. Chin J Biol. 2014; 216210. Retraction: Palaneeswari S et al. Chin J Biol. 2019;1735489.

33. Orr S, Bridges C. Chronic kidney disease and exposure to nephrotoxic metals. Int. J Mol Sci. 2017;18(5):1039.

34. Satarug $S$ et al. Kidney cadmium toxicity, diabetes and high blood pressure: the perfect storm. Tohoku J Exp Med. 2017;241:65-87.

35. Jankowska M et al. Vitamins and microelement bioavailability in different stages of chronic kidney disease. Nutrients 2017;9(3):282.

36. Prodanchuk $M$ et al. Disturbances of trace element metabolism in ESRD patients receiving hemodialysis and hemodiafiltration. Cent European J Urol. 2013;66(4):472-6.

37. Długaszek M et al. Magnesium, 
calcium and trace elements distribution in serum, erythrocytes, and hair of patients with chronic renal failure. Magnes Res. 2008;21(2):109-17.

38. Lokesh $\mathrm{S}$ et al. Trace elements in chronic haemodialysis patients and healthy individuals-a comparative study. J Clin Diagn Res. 2016;10(10):14-7.

39. Raoofi R et al. Copper and zinc serum level in patients receiving hemodialysis. Online J Biol Sci.

$$
\text { 2015;15(4):217-20. }
$$

40. Balla S, Ismail A. Impact of hemodialysis on serum zinc and copper level in CKD patients. J App Pharm Sci. 2016;6(4):165-8.

41. Pokusa M, Trančíková A. The central role of biometals maintains oxidative balance in the context of metabolic and neurodegenerative disorders. Oxid Med Cell. 2017;1-18.

42. Guo C, Wang C. Effects of zinc supplementation on plasma copper/ zinc ratios, oxidative stress, and immunological status in hemodialysis patients. Int J Med Sci. 2013;10(1):7989.

43. Guo $\mathrm{C}$ et al. $\mathrm{Cu} / \mathrm{Zn}$ ratios are associated with nutritional status, oxidative stress, inflammation and immune abnormalities in patients on peritoneal dialysis. Clin Biochem. 2010;44(4):275-280. 